\title{
Self-initiation of antiretroviral therapy in the developing world: the involvement of private pharmacies in an HIV program
}

This article was published in the following Dove Press journal:

Drug, Healthcare and Patient Safety

28 March 2012

Number of times this article has been viewed

\section{Omary Mashiku Minzi' \\ Deus Buma² \\ Godeliver A Kagashe 3}

'Unit of Pharmacology and Therapeutics, School of Pharmacy, Muhimbili University of Health and Allied Sciences, Dar Es Salaam, Tanzania; ' 2 Department of Pharmaceutics, School of Pharmacy, Muhimbili University of Health and Allied Sciences, Dar Es Salaam, Tanzania; Department of Pharmacy, Muhimbili National Hospital, Dar Es Salaam, Tanzania; ${ }^{3}$ Department of Pharmacy, Muhimbili National Hospital, Dar Es Salaam, Tanzania
Correspondence: OM Minzi

Unit of Pharmacology and Therapeutics, School of Pharmacy, Muhimbili University of Health and Allied Sciences, PO BOX 65013, Dar Es Salaam, Tanzania

$\mathrm{Tel}+255754394715$

Fax +25522 2150465

Email ominzi@muhas.ac.tz
Background: Self-initiation to antiretroviral treatment (ART) exposes the patient to the risk of drug toxicity, poor adherence to treatment, and escalates the development of drug resistance.

Objectives: To determine the sources of antiretroviral (ARV) drugs by unregistered human immunodeficiency virus (HIV)-infected patients and the extent of ARV self-medication.

Methods: Simulated clients were used to investigate availability and ARV dispensing practice in the private pharmacies in Dar Es Salaam, Tanzania. A total of $480 \mathrm{HIV}$-infected patients qualifying to start ART were interviewed to find out their previous use of ARV drugs prior to visiting the HIV clinics. Venous blood $(2 \mathrm{~mL})$ was collected from each patient who indicated not to have used ARVs in the past $(n=450)$. Blood samples were analyzed for the presence and levels of nevirapine (NVP).

Results: Only 5.1\% (23/451) of pharmacies were found stocking ARVs drugs, among which $4.0 \%$ were retail. Drug dispensers in nearly all (15/18) retail pharmacies which stocked ARVs were willing to sell ARVs without prescription. Out of 450 enrolled patients, only $2.7 \%$ (12) stated that they had been receiving ARV drugs from HIV clinics but interrupted the ART treatment due to various reasons. From 450 patients, only 10\% had quantifiable NVP concentrations in the blood, despite stating in an interview that they had not recently used ARVs.

Conclusion: Prior use of ARV drugs outside HIV clinics was rare among patients attending those centers. However, the results show that some patients could access and use ARV drugs from private pharmacies without undergoing ART eligibility assessment in HIV clinics.

Keywords: ART naïve patients, antiretroviral drugs, dispensing practices

\section{Introduction}

Human immunodeficiency virus (HIV) infection is currently ranked as the number two killer disease after malaria in sub-Saharan Africa. ${ }^{1}$ Most governments in this region started providing antiretroviral treatment (ART) in 2005. The World Health Organization (WHO) has set criteria for initiation of ART for developing countries, which require an HIV-infected patient to have a CD4 count of $<350$ cell/ $\mu \mathrm{L}$ or acquired immune deficiency syndrome (AIDS)-related illnesses regardless of CD4 count. ${ }^{2}$ HIV-infected patients are required to attend HIV clinics for assessment to ensure that they meet criteria for ART initiation. Patients can then get an antiretroviral (ARV) prescription from a clinician so as to access the ARV drugs from HIV clinics. Not going through HIV clinics, and self-initiation of ART, exposes the patient to risk of using the drugs with contraindicated conditions. In this case, patients also miss important information such as consequences of treatment interruptions, management of ARV drug toxicities, and advantages of adherence to ART. ${ }^{3-7}$ 
To complement the effort of governments in the provision of free ART to all HIV-infected patients in sub-Saharan Africa, the private sector also provides ARVs to eligible patients who are registered in HIV clinics. Unfortunately, availability of ARVs in private pharmacies enhances increased access to ARVs, even to those who are not yet assessed and registered to start using ARVs. In addition, provision of drugs through private drug outlets has been reported to be associated with irrational dispensing of important medicines such as antibiotics. ${ }^{8-11}$ In developing countries, many people have been reported to initially visit pharmacies to seek medication and medical information when they fall sick..$^{9-11}$ Considering the stigma associated with HIV infection, it is highly probable that some patients may initially try to access ARVs from pharmacies. In this case, patients are not assessed for ART eligibility and hence miss adequate counseling on treatment adherence and management of ARV drug toxicities. ${ }^{12,13}$

Therefore, this study was undertaken to determine the extent of sourcing and using ARVs without undergoing assessment at HIV clinics for ART eligibility. The possibility of HIV patients accessing ARVs from private drug outlets and ARV drug dispensing practices in private pharmacies is hereby reported.

\section{Experimental}

\section{Study area}

This cross-sectional study involved 451 private pharmacies and two HIV clinics at Muhimbili National Hospital and Mwanayamala District Hospital. Muhimbili National Hospital is one of the few referral hospitals in the country and is the biggest hospital in the country. Mwananyamala is a district hospital located in the Kinondoni district in Dar Es Salaam. The study pharmacies and hospitals are all located in Dar Es Salaam, Tanzania. The study took place between January and July 2010. A total of 480 HIV-positive outpatients (adults and adolescents, both males and females) from the two HIV clinics were interviewed. Nurses and counselors of each HIV clinic were involved in identification of those patients who were assessed by HIV clinicians and found to be eligible to start ART on the week when research assistants visited the clinics. The patients were selected based on the first-in, first-taken principle, as long as each one met the inclusion criteria.

\section{Assessment of ARVs prior to use outside HIV clinics}

Patients were interviewed to find out their previous use of ARV drugs before visiting the HIV clinic. The inclusion criterion for patient recruitment was HIV-infected patient qualifying to start ART after undergoing assessment for ART initiation. In total, 480 patients were enrolled in the study after consenting and meeting other eligibility criteria. Each patient who stated not to have used antiretroviral drugs before registering at the clinic was requested to allow a phlebotomist to collect a single venous blood $(2 \mathrm{~mL})$ from his/her arm.

Venous blood was collected from 450 HIV-infected patients after they had consented. The samples were centrifuged immediately at $1500 \mathrm{~g}$ for 10 minutes, and the obtained plasma was kept at $-80^{\circ} \mathrm{C}$ until assay.

The plasma samples were analyzed for concentrations of nevirapine (NVP) using a high performance liquid chromatography (HPLC) method developed by the authors. Details of the method have been published elsewhere. ${ }^{14}$ The levels of NVP were used as an indication of recent use of ARV drugs.

\section{Assessment of ARVs dispensing practice in private pharmacies}

Assessment of ARV drug dispensing practice in private pharmacies involved 451 pharmacies, among which, 51 were wholesale. The pharmacies were selected based on accessibility and whether the premises were still active. Information on the status of the pharmacies was provided by drug regulatory agencies of the Ministry of Health. Data collection was done using simulated clients (SC).

The SC posed as a relative of an HIV-infected patient whose CD4 count was below 200 cells/ $\mu \mathrm{L}$. The SC stated that his relative had been on ART in another town but had recently moved to Dar Es Salaam. Then, he asked if there was a possibility of buying ARVs from the pharmacy while waiting for his relative to be enrolled in another HIV clinic in Dar As Salaam. The second SC had an ARV prescription claimed to have been written at a private dispensary, but the prescription did not have the name of the dispensary, the address, or the name of the prescriber. The SC requested a combination of stavudine/zidovudine, lamivudine, and nevirapine drugs from the pharmacies.

\section{Ethical issues}

Verbal and written informed consent was sought from the participants. Ethical clearance was granted by the Muhimbili University of Health and Allied Sciences (MUHAS) ethics committee.

\section{Data analysis}

The proportion of HIV-infected patients who had previously used ARVs before attending the HIV clinic was determined. The proportion of HIV-infected patients who stated not to 
have used ARVs previously but had a quantifiable level of NVP in their blood samples was also determined. The data was used to determine the proportion of patients who were not naïve to ART. Data obtained from the private community pharmacies was used to determine the proportion of premises that served as possible sources of ARVs to some patients who bypassed HIV clinics.

\section{Results}

\section{ARV drug use prior to attending HIV clinic}

Table 1 describes their demographic characteristics, and it can be seen that the majority of the study patients in both clinics were female and aged 26-35 years. Blood samples were able to be taken from 450 patients after consenting to participate in the study. All regimens used were triple ARV combination therapy and contained nevirapine. The combinations which were highly recommended as first-line options at that time were: AZT (zidovudine) + 3TC (lamivudine) + NVP or $4 \mathrm{dT}$ (stavudine) $+3 \mathrm{TC}+\mathrm{NVP}$. However, the treatment guidelines have changed and currently the mostly prescribed combination is AZT + 3TC + EFV unless the patient is woman with childbearing potential.

Out of these patients, only $2.7 \%$ (12) acknowledged that they had received ARVs from HIV clinics in the past but interrupted the treatment due to various reasons including lack of fare money to travel to HIV clinics, experiencing drug

Table I Demographic characteristics of the study patients, $\mathrm{N}=480$

\begin{tabular}{|c|c|c|}
\hline \multirow[t]{2}{*}{ Characteristic } & \multicolumn{2}{|l|}{$\mathbf{N}(\%)$} \\
\hline & MLH, N = 408 & $\mathbf{M N H}, \mathbf{N}=\mathbf{7 2}$ \\
\hline \multicolumn{3}{|l|}{ Gender } \\
\hline$M$ & $150(37)$ & $24(33)$ \\
\hline $\mathrm{F}$ & $258(63)$ & $48(67)$ \\
\hline \multicolumn{3}{|l|}{ Age (years) } \\
\hline $15-25$ & $46(11.3)$ & $8(I 1 . I)$ \\
\hline $26-35$ & $193(47.3)$ & $29(40.3)$ \\
\hline $36-45$ & I I4 (27.9) & $25(34.7)$ \\
\hline $46-55$ & $32(7.8)$ & $9(12.5)$ \\
\hline $56+$ & $23(5.7)$ & I ( I.4) \\
\hline \multicolumn{3}{|l|}{ Education level } \\
\hline No formal school & $25(6.1)$ & I (I.4) \\
\hline Primary school & $310(76)$ & $44(61.1)$ \\
\hline Secondary school & $59(14.5)$ & I7 (23.7) \\
\hline Post secondary school (certificate) & I I (2.7) & $5(6.9)$ \\
\hline College education (diploma) & $3(0.7)$ & $5(6.9)$ \\
\hline \multicolumn{3}{|l|}{ Occupation } \\
\hline Not employed & I I 6 (28.5) & $16(22.2)$ \\
\hline Self employed & $223(54.7)$ & $32(44.4)$ \\
\hline Employed & $69(16.8)$ & $24(33.3)$ \\
\hline
\end{tabular}

Abbreviations: F, female; M, male; MLH, Mwananyamamala HIV Clinic; MNH, Muhimbili HIV Clinic. toxicity, and inadequate supply of ARV at the clinics at which they were registered. The patients had NVP concentration of $<0.05 \mu \mathrm{g} / \mathrm{mL}$ (the limit of quantification of the method used). ${ }^{14}$ Of the 450 blood samples collected from a similar number of HIV-infected patients, $10 \%$ had quantifiable nevirapine concentrations, despite the patients stating that they had never used ARVs in the past. The blood samples from these patients who claimed to be ART naïve in an interview had nevirapine plasma concentrations ranging between 0.2 and $4.4 \mu \mathrm{g} / \mathrm{mL}$ (median $0.92 \mu \mathrm{g} / \mathrm{mL}$ ) (Table 2). Adding together those who had interrupted ARV use and those who had detectable levels of NVP in blood, made a total of $14 \%$ (67/480) of the patients who had used ARV drugs, and all were presumed to be new patients.

\section{ARV dispensing practice in pharmacies}

A total of 451 pharmacies were visited. These included 400 retail and 51 wholesale pharmacies. Only 5.1\% (23/451) of the visited pharmacies stocked ARVs, among which about $1 \%$ were wholesale pharmacies. Using an SC technique, it was found that $4.5 \%$ (18) of the retail pharmacies stocked ARVs, and nearly all of them (15/18) were willing to sell the drugs to any patient as long as the SC indicated that his patient had CD4 counts below 200 cells/ $\mu \mathrm{L}$. The same number of pharmacies were willing to dispense ARVs to the SC who had a prescription which did not bear the name of the dispensary and had no signature of the prescriber.

All the wholesale pharmacies that stocked ARVs $(n=5)$ by that time also dispensed the drugs to patients who presented ART prescriptions and CD4 count filled forms from recognized HIV clinics.

\section{Discussion}

This study confirmed by the use of HPLC plasma analysis that the majority (90\%) of new HIV patients enrolled for ART

Table 2 Proportion of patients in relation to previous drug use and ARV drug level obtained in patients who consented to give a blood sample $(\mathrm{N}=450)$

\begin{tabular}{lll}
\hline & $\begin{array}{l}\text { \% of patients } \\
(\mathbf{N})\end{array}$ & $\begin{array}{l}\text { Obtained NVP plasma } \\
\text { concentrations, } \\
\mu \mathrm{g} / \mathrm{mL}\end{array}$ \\
\hline $\begin{array}{l}\text { Stated to have acquired } \\
\text { ARV previously from } \\
\text { HIV clinics }\end{array}$ & $2.7(12)$ & $<0.05$ \\
$\begin{array}{l}\text { Stated to have not used } \\
\text { ARV, despite having NVP } \\
\text { in their blood samples }\end{array}$ & $10(45)$ & $0.25-4.40$ \\
\begin{tabular}{l} 
Total \\
\hline
\end{tabular} & $12.7(67)$ & \\
\hline
\end{tabular}

Abbreviations: $A R V$, antiretoviral; $H I V$, human immunodeficiency virus; NVP, nevirapine. 
initiation were indeed ARV naïve. Only $2.7 \%$ of the patients acknowledged that they had previously obtained the ARVs from HIV clinics but interrupted the treatment due to various reasons including drug toxicity and inability to visit the clinics. The blood samples from 45 (10\%) patients purported to be ART naïve had nevirapine plasma concentrations ranging between 0.2 and $4.4 \mu \mathrm{g} / \mathrm{mL}$ (median $0.92 \mu \mathrm{g} / \mathrm{mL}$ ) (therapeutic range of nevirapine is $2-5 \mu \mathrm{g} / \mathrm{mL}),{ }^{15,16}$ although they stated in an interview that they had not recently used ARV drugs. This implies that such patients had been selftreating with ARVs without undergoing pre-ART assessment at HIV clinics.

In this study, $2.7 \%$ patients stated that they had interrupted the ARV medication due to various reasons. ART defaulters do resume HIV clinic visits with a deteriorated health condition and have been reported to end up with poor treatment outcomes. ${ }^{6,17}$ Better treatment prognosis is associated with adherence to treatment and naivety to ARV drugs. ${ }^{5,18}$ Those HIV-infected patients who delay visiting the clinics are likely to suffer the risk of starting ART when they have too low CD4 count to sustain cure. ${ }^{7}$

This study has shown that pharmacies stocking ARVs were willing to sell the drugs to patients/clients who claimed to have CD4 count $<200$ cells $/ \mu \mathrm{L}$. These pharmacies also sold ARVs to patients who did not have genuine ART prescriptions. The possibility of obtaining ARVs from pharmacies without providing a prescription from an HIV clinic enhances the behavior of self-medication with ARV drugs. The authors found out that even some of the wholesale pharmacies were practicing retail activities. Drug provision in developing countries is often poorly regulated, and some of the drug outlets dispense drugs illegally. ${ }^{8-11}$ This present study has shown that there was irrational dispensing of ARV drugs in the private pharmacies. Patients could just mention their sero-status and obtain ARV drugs without having a genuine ARV prescription written by a prescriber working at the HIV clinics. Availability of even a single center with unregulated ARV drug provision creates a loophole for those patients who would like to bypass HIV clinics. This in turn has a negative impact on the roll-out of an ART program and affects the government's political will to curb the pandemic.

Dangers of bypassing an HIV clinic assessment for ART initiation include discontinuation of the treatment after experiencing drug toxicity ${ }^{17}$ or using the drugs with contraindicated conditions. For instance, it was recently reported that hypersensitivity reactions affected some HIV-infected women who used NVP-based highly active ART with CD4 counts higher than 350 cells $/ \mu \mathrm{L} .{ }^{19}$ ART interruption exposes the HIV patient to risk of developing drug resistance. Proper use of antiretroviral therapy in HIV-1 infection enhances treatment outcomes and immunological recovery. ${ }^{18}$

\section{Limitations}

The small sample size of pharmacies which were stocking ARVs is a limitation of this study. The study was conducted in only one region (Dar es Salaam), where the Ministry of Health and medical and drug regulatory agencies are located. This may have an influence on the practice of HIV clinics and the private pharmacies.

The study involved only two HIV clinics, both of which have a good number of trained HIV health workers involved in the care and treatment of HIV patients. Furthermore, a great deal of community sensitization campaigns on effective use of HIV clinics has been conducted in Dar es Salaam, and many people have timely access to the information due to presence of mass communication media. It is possible that the magnitude of the problem could be higher in the up-country. It is therefore recommended that a similar study be conducted in other regions by involving a bigger number of HIV clinics and patients.

\section{Conclusion}

The findings of this study indicate that the majority of the patients were naïve to ART prior to visiting HIV clinics. Therefore, it can be extrapolated that the use of ARV drugs outside HIV clinics was rare among patients visiting these centers. However, some patients could access and use ARVs from private pharmacies without undergoing ART eligibility assessment in HIV clinics, thus highlighting the likely setbacks in involving private pharmacies in the provision of ARV drugs in the HIV programs of developing countries.

\section{Acknowledgments}

This study was funded by a Swedish cooperation for developing countries (Sida) through the Directorate of Research and Publications at MUHAS. The Ministry of Health and Social Welfare of Tanzania also gave financial support. The authors thank all the research assistants, the health care workers at the HIV clinics, and the drug dispensers in pharmacies.

The authors also thank all patients for their willingness to participate in the study. Dr Philip Sasi and Dr Apolinary Kamuhabwa were helpful in proofreading the manuscript. 


\section{Disclosure}

The authors report no conflicts of interest in this work.

\section{References}

1. UNAIDS. Report on the Global AIDS epidemic. New York: UNAIDS; 2002.

2. World Health Organization. Scaling up antiretroviral therapy in resourcelimited settings. Guidelines for a public health approach. Geneva, Switzerland: World Health Organization; 2003.

3. Foisy MM, Gough K, Quan CM, Harris K, Ibanez D, Phillips A. Hospitalization due to adverse drug reactions and drug interactions before and after HAART. Can J Infect Dis. 2000;11:193-201.

4. Montessori V, Press N, Harris M, Akagi L, Montaner JS. Adverse effects of antiretroviral therapy for HIV infection. CMAJ. 2004;170:667-672.

5. Wester CW, Okezie OA, Thomas AM, Bussmann H. Higher-thanexpected rates of lactic acidosis among highly active antiretroviral therapy-treated women in Botswana: preliminary results from a large randomized clinical trial. AIDS. 2007;46:318-322.

6. Holkmann Olsen C, Mocroft A, Kirk O, et al. Interruption of combination antiretroviral therapy and risk of clinical diseases progression to AIDS or death. HIV Med. 2007;8:96-104

7. Rodriguez-Arenas MA, Jarrin I, del Amo J, et al. Delay in the initiation of HAART, poorer virological response, and higher mortality among HIV-infected injection drug users in Spain. AIDS Res Hum Retroviruses. 2006;22:715-723.

8. Rattan A, Kumar A. Antibiotics - use and misuse. J Acad Hosp Adm. 1995;7:19-22.

9. Stenson B, Syhakhang L, Ericksson B, Tomson G. Real world pharmacy: assessing the quality of private pharmacy practice in Lao People's Democratic Republic. Soc Sci Med. 2001;52:393-404.
10. Goodman C, Kachur SP, Abdulla S, Bloland P, Mills A. Drug shop regulation and malaria treatment in Tanzania - why do shops break the rules, and does it matter? Health Policy Plan. 2007;22:393-403.

11. Goel P, Ross-Degnan D, Berman P, Soumerai S. Retail pharmacies in developing countries: a behavior and intervention framework. Soc Sci Med. 1996;42:1155-1161.

12. Rawlings MK, Smith KY. Recognizing and managing common toxicities in patients receiving antiretroviral therapy. AIDS. 2004;14:12-15.

13. Wood E, Montaner JS, Yip B, Tyndall MW. Adherence and plasma HIV RNA responses to HAART among HIV-1 infected injection drug users. CMAJ. 2003;169:656-661.

14. Minzi O, Ngaimisi E. Bioanalytical method for determination of nevirapine in-vivo in resource constrained laboratories. J Chem Pharm Res. 2010;2:431-439.

15. Rendón A, Núñez M, Jiménez-Nácher I, González de Requena D, González-Lahoz J, Soriano V. Clinical benefit of interventions driven by therapeutic drug monitoring. HIV Med. 2005;6:360-365.

16. de Maat MM, Huitema AD, Mulder JW, et al. Subtherapeutic antiretroviral plasma concentrations in routine clinical outpatient HIV care. Ther Drug Monit. 2003;25:367-373.

17. Wit FW, Kesselring AM, Gras L, et al. Discontinuation of nevirapine because of hypersensitivity reactions in patients with prior treatment experience, compared with treatment-naive patients: the ATHENA cohort study. Clin Infect Dis. 2008;46:933-940.

18. Battegay M, Nuesch R, Hirschel B, Kaufmann GR. Immunological recovery and antiretroviral therapy in HIV-1 infection. Lancet Infect Dis. 2006;6:280-287.

19. Knobel H, Guelar A, Montero M, Carmona A, Luque S, González A. Risk of side effects associated with the use of nevirapine in treatmentnaïve patients, with respect to gender and CD4 cell count. HIV Med. 2008;9:14-18.
Drug, Healthcare and Patient Safety

\section{Publish your work in this journal}

Drug, Healthcare and Patient Safety is an international, peer-reviewed open-access journal exploring patient safety issues in the healthcare continuum from diagnostic and screening interventions through to treatment, drug therapy and surgery. The journal is characterized by the rapid reporting of reviews, original research, clinical, epidemiological and

\section{Dovepress}

post-marketing surveillance studies, risk management, health literacy and educational programs across all areas of healthcare delivery. The manuscript management system is completely online and includes a very quick and fair peer-review system. Visit http://www.dovepress.com/ testimonials.php to read real quotes from published authors. 